\title{
Closure of Periodontal Flap with N Butyl Cyanoacrylate: A Report of Three Cases with Literature Review
}

\section{Dr. Shababe Saquib Abullais}

Assistant Professor, Department of periodontics and Community Dental Sciences, College of

Dentistry, King Khalid University. Abha, KSA.

\section{Dr. Mukhatar Ahmed Javali}

Associate Professor, Department of periodontics and Community Dental Sciences, College of

Dentistry, King Khalid University. Abha, KSA.

\section{Dr. Mohammad Yunis Saleem Bhat}

Associate Professor, Department of periodontics and Community Dental Sciences, College of

Dentistry, King Khalid University. Abha, KSA.

\section{Dr. Mohasin Abdul khader}

Assistant Professor, Department of periodontics and Community Dental Sciences, College of

Dentistry, King Khalid University. Abha, KSA.

\section{Dr. Amit Chavan}

Assistant professor,Department of periodontics, D.Y. Patil Dental College and Hospital, Navi Mumbai

\begin{abstract}
:
Introduction: The periodontal flap is one of the most frequently employed procedures, particularly for moderate to deep pockets. The tight adaptation of tissues following flap surgery is conventionally achieved by sutures. Sutures have a phenomenon of 'wicking' which makes it a site for secondary infection. Tissue adhesives have been developed as alternatives to overcome these problems.
\end{abstract}

Case report: This case series consist of three cases. After completion of phase I therapy the patients were assigned for flap surgery depending on the pocket depth. At the end of flap surgery flap closure was done by $N$ butyl cyanoacrylate tissue adhesive material. Evaluation of the cases were done at 1week, 3 week and 6 week for the progress of healing.

Conclusion: No adverse reaction and uneventful healing is observed when Cyanoacrylate is used as tissue adhesive for the adaptation of flap after periodontal flap surgery.

Keywords: Cyanoacrylate, periodontal flap, flap surgery, suture.

\section{INTRODUCTION}

Periodontitis is a multifactorial disease resulting in inflammation with destruction of the connective tissue attachment of the teeth. Periodontitis exists in three primary forms: Chronic periodontitis is most common amongst the three forms i.e. Chronic Periodontitis, Aggressive Periodontitis and Periodontitis as a manifestation of systemic disease. Periodontal pocket formation is usually a squeal of the disease process. Severity of periodontitis can be determined by periodontal pocket depth. Mild, moderate and severe periodontitis has pocket depth of $>3$ and $<5 \mathrm{~mm}, \geq 5$ and $<7 \mathrm{~mm}$ and $\geq 7 \mathrm{~mm}$ respectively. ${ }^{1}$ The periodontal flap is one of the most frequently employed procedures, particularly for moderate to deep pockets.

Flap surgery for periodontal re-attachment, demands close post- operative adaptation of the mature, gingival connective tissue on to the prepared tooth surface. ${ }^{2,3,4}$

This adaptation must be maintained for sufficient period of time, which in turn will permit reorganization of the connective tissue. The tight adaptation of tissues following flap surgery is conventionally achieved by sutures.

As inflammatory reactions in the mucosa and the gingiva are found to be more rapid and intense, the tissue trauma due to the penetration of the suture needle enhances the same. Braided silk is the most common suture used for closure of oral wounds. It has a phenomenon of 'wicking' which makes it a site for secondary infection. ${ }^{5,6,7}$ In order to overcome these difficulties, a need for an alternative to sutures is always felt. 
Tissue adhesives have been developed as alternatives to overcome these problems. Cyanoacrylates is a tissue-adhesive material that promotes the rapid adhesion of soft and hard tissues synthesized in 1959. 8 "9 The chemical formula for cyanoacrylate is $\mathrm{H}_{2} \mathrm{C}=\mathrm{C}(\mathrm{CN}) \mathrm{COOR}$, where $\mathrm{R}$-can be substituted for any alkyl group ranging from methyl to decyl. There are several forms of cyanoacrylate available, and have been studied for possible use in humans. Alpha and ethyl forms were found incompatible for use in humans. Particular interest has focused on the use of n-butyl cyanoacrylate, which is biocompatible for use in humans.

Cyanoacrylates have been used in the closure of organs, skin, mucosa grafts, closure of lacerations and incisions, post-extraction dressings in dentistry and even in the fixation of mandibular fractures. Cyanoacrylates have favorable qualities like; strong bonding, polymerization time, biodegradability, bacteriostatic ability and good hemostatic property.

\section{CaSe RePort}

\section{Case1}

A 40 year male patient with a noncontributing medical history visited to the Department of Periodontology with the chief complaint of bleeding gums and oral malodor. Clinical examination revealed abundance of local factors, severe gingival inflammation, deep periodontal pocket of around $>7 \mathrm{~mm}$ and grade I mobility in lower anterior teeth. Radiographic examination revealed generalized horizontal bone loss. On the basis of clinical finding and radiographic examination a diagnosis of generalized chronic periodontitis was established. Treatment plan advised to the patient was thorough scaling and root planing followed by periodontal flap surgery for remaining pockets.

\section{Case2}

A 37 year female patient with a noncontributing medical history visited to the Department of Periodontology with the chief complaint of swollen gums and oral malodor. Clinical examination revealed abundance of local factors, papillary gingival enlargement, deep periodontal pocket of around $>6 \mathrm{~mm}$. Radiographic examination revealed generalized horizontal bone loss. On the basis of clinical finding and radiographic examination a diagnosis of generalized chronic periodontitis was established. Treatment plan advised to the patient was thorough scaling and root planing followed by periodontal flap surgery for remaining pockets.

\section{Case3}

A 42 year male patient with a noncontributing medical history visited to the Department of Periodontology with the chief complaint of oral malodor. Clinical examination revealed abundance of local factors, deep periodontal pocket of around $>6 \mathrm{~mm}$. Radiographic examination revealed generalized horizontal bone loss. On the basis of clinical finding and radiographic examination a diagnosis of generalized chronic periodontitis was established. Treatment plan advised to the patient was thorough scaling and root planing followed by periodontal flap surgery for remaining pockets.

\section{TREATMENT DELIVERED}

Informed consent was obtained from each patient before starting the treatment. Thorough scaling and root planing was performed as a part of phase I therapy then patient was kept on the maintenance phase for one month. After one month patient was examined for the remaining pockets (Fig.1a, 2a, $3 a)$. Revaluation of the periodontal condition revealed pockets of $>5 \mathrm{~mm}$ in the interproximal areas. Periodontal flap surgery was advised to the patient as a part of phase II therapy for pocket reduction.

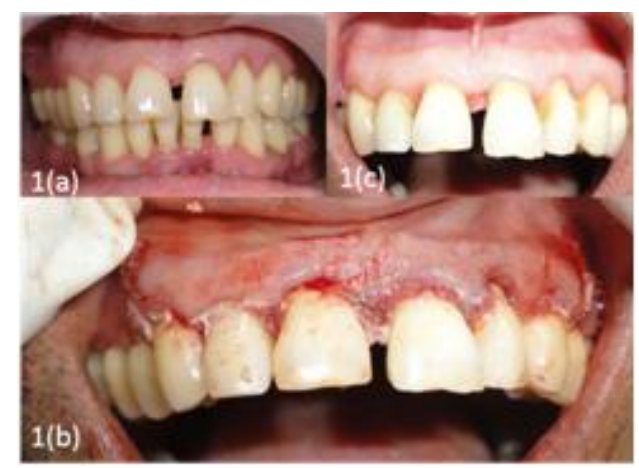

Figure1(a). Pre-operative view, after phase I therapy, 1(b). Cyanoacrylate applied at flap margin, 1(c). Postoperative view after 42 days 
The surgical procedure consisted of a full thickness mucoperiosteal flap elevation. After administration of the local anesthesia, incisions were made with number 15 Bard Parker blade. Two vertical releasing incisions were made with number 11 Bard Parker blade. Then the full thickness flaps were reflected so as to expose the root surface and the crest of the bone. The surgical area was debrided so as to remove the granulation tissue. The root surface was planed to remove any calculus and irregularities. Thorough irrigation was done prior to closure of the area with cyanoacrylate. The cyanoacrylate was placed in drop wise manner on the flap margins, which were held in place. (Fig $1 b, 2 b, 3 b$ ) The application was done till a thin film of set cyanoacrylate formed.

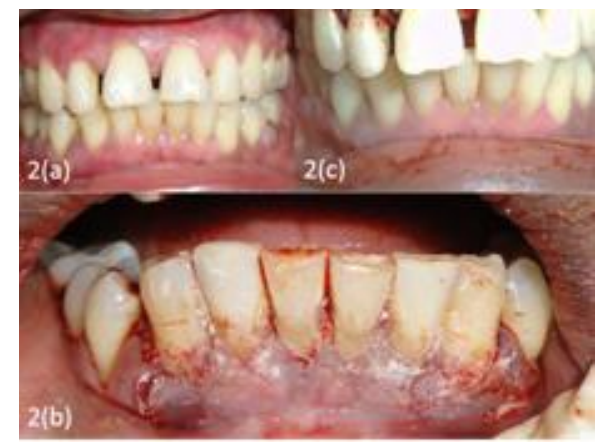

Figure 2(a). Pre-operative view, after phase I therapy, 2(b). Cyanoacrylate applied at flap margin, 2(c). Postoperative view after 42 days

Standard post-operative instructions were given. Antibiotics and analgesics were prescribed. Patients were recalled on the $7^{\text {th }}$ day for removal of the cyanoacrylate material. The surgical site was evaluated for healing at 1 week, 3 week and 6 week, which showed uneventful heeling of the same (Fig 1c, 2c, $3 c)$.

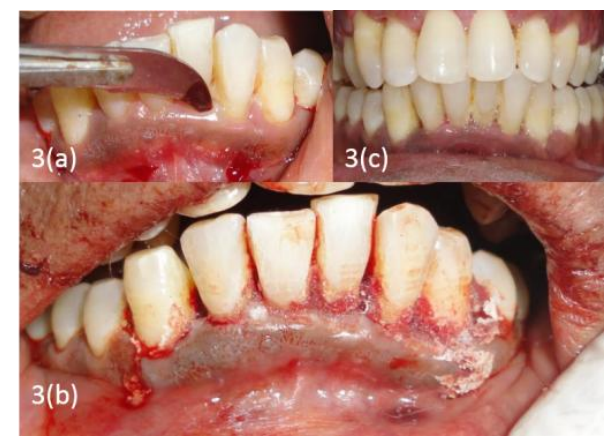

Figure 3(a). Preoperative view, after phase I therapy, 3(b). Cyanoacrylate applied at flap margin, 3(c). Postoperative view after 42 days

\section{DISCUSSION}

Periodontitis is an infectious disease involving the periodontium, resulting in destruction of the connective tissue attachment of the teeth. Periodontal flap surgery is one the most widely used treatment modality for pocket reduction in the treatment of periodontitis. Flap closure is the important step in the flap surgery procedure. Braided silk is the most commonly used suture material for approximating the flap margins together after periodontal flap surgery, ${ }^{2}$ whereas cyanoacrylates are the most widely used tissue adhesives for closure of traumatized as well as incision wounds. ${ }^{11,13,14}$

The present case series consist of 3 cases; all the patients were systemically healthy. All the patients were kept on maintenance phase of one month after the completion of phase I therapy. After one month pockets were evaluated for the periodontal flap surgery. Area with the pocket depth of more than $5 \mathrm{~mm}$ were assigned for the surgery. ${ }^{15}$

The cyanoacrylate material used in the present study was n-butyl cyanoacrylate (NBC). This material has got good bonding properties and bond strength to hold the tissue margins together, ${ }^{(11,14)}$ it has good hemostatic property ${ }^{16}$ and to some extent it is also bacteriostatic in nature. ${ }^{17}$ It also has good working properties like flow and fast setting (within 5 to 10 seconds).

Cyanoacrylate when compared with the silk suture for closure of periodontal flap, it was found in studies that; when the plaque scores were compared between the suture and the cyanoacrylate sites 
clinically the suture site was found to accumulate more plaque as compared to the cyanoacrylate site.

${ }^{18.19}$ Gingival index scores between the suture and the cyanoacrylate sites showed a significant difference with suture site exhibiting increased score. This can be attributed to presence of the silk material within the tissues, which might have provoked the response. ${ }^{5,19}$ Some studies showed increased inflammatory response of the flap to silk because silk being a foreign protein, is treated as such by the body, and it has tendency to fragment the wound. ${ }^{2,5}$ Whereas some author attributed it to the trauma during suturing resulting in increased inflammation and also to increased plaque accumulation at the suture site. ${ }^{19}$

\section{REFERENCES}

[1] American Academy of Periodontology Task Force Report on the Update to the 1999 Classification of Periodontal Diseases and Conditions J Periodontol. 2015; 86:835-8.

[2] Levin MP. "Periodontal suture materials and surgical dressings." Dent Clinic of North Am. $1980 ; 24: 767-81$.

[3] Ramfjord S.S. "Surgical Pocket Therapy.” Int Dent J. 1977; 27:263-9.

[4] Takei H. Carranza F. Jr. "The periodontal flap" In Carranza FA. Neumann M (ed), Clinical Periodontology, Published by W.B. Suanders and company. $8^{\text {th }}$ edn. 1996:592-604.

[5] Macht SD., Krizek TJ. "Sutures and suturing-Current concepts." J Oral Surg. 1978: 36:710-3.

[6] Castelii W.A., Nasjleti C.F., Caffesse R.E., Diaz - Perez R. "Gingival response to silk, cotton and nylon suture materials". Oral Surg. 1978; 45:179-85.

[7] Castelii W.A., Nasjleti C.F., Diaz - Perez R., Caffesse R.E. "Cheek mucosal response to silk, cotton and nylon suture material". Oral Surg. 1978;45:186-9.

[8] Ahn D.K., Sims C.D., Randolph M.A., et al: Craniofacial skeletal fixation using biodegradable plates and cyanoacrylate glue. Plast Reconstr Surg. 1997;99:1508

[9] Singer A.J., and Thode H.C.: A review of the literature on octyl-cyanoacrylate tissue adhesive. Am J Surg. 2004;187:238

[10] Torumi DM., O'Grady K. "Surgical tissue adhesives in otolaryngology-head and neck surgery." Oto Laryn Clin of North Am. 1994; 27:203-9.

[11] McGraw V.A., Caffesse R.G. "Cyanoacrylates in Periodontics." J. West Soc of Periodontol abstracts. 1978; 26:4-13.

[12] Bessermann M. "Cyanoacrylate spray in the treatment of prolonged oral bleeding". Int J Oral Surg. 1977; 6:233-40.

[13] McGraw VA., Caffesse RG., Nasjlati CE. "Healing of periodontal flaps following use of MBR4197 (fluacrylate) in rhesus monkeys. A biometric and histometric evaluation." J Peridontol. 1979; 50:305-10.

[14] Herod EL. "Cyanoacrylates in dentistry: A review of literature." J Canadian Dent Asso. 1990; 56:331-4.

[15] Caffesse RG, Sweeney PL, Smith BA. Scaling and root planing with and without periodontal flap surgery. J Clin Periodontol. 1986; 13:205-10.

[16] Greer R.O.Jr, "Studies concerning the histotoxicity of isobutyl-2-cyanoacrylate tissue adhesive when employed as an oral hemostat." Oral Surg. 1975; 40:659-69.

[17] Jandinski .J., Sonis S. "In vitro effects of isobutyl cyanoacrylate on four types of bacteria." J Dent Res. 1971; 1557-8.

[18] Kulkarni S., Dodwad V., Chava V. "Healing of periodontal flaps when closed with silk sutures and n- butyl cyanoacry late: A clinical and histological study." Indian J Dent Res. 2007; 18:72-7.

[19] Giray C.B., Sungur A.,Atasever A., Araz K. "Comparison of silk sutures and n-butyl-2cyanoacrylate on healing of skin wounds. A pilot study." Aust Dent J. 1995; 40:40-3. 